\title{
Non-adjuvant Single Low Dose Bevacizumab Intravitreal Injection Causes Resolution of Choroidal Metastases from Breast Carcinoma
}

\author{
L Mowatt
}

\begin{abstract}
INTRODUCTION
Choroidal metastasis occurs in $7-11 \%$ of patients with breast carcinomas (1). Treatment includes external beam radiation therapy, tamoxifen, aromatase inhibitors (letrozole) and chemotherapy, including systemic bevacizumab (1-3). Bevacizumab, a monoclonal antibody, is anti-angiogenetic, thereby limiting tumour vascularization and growth. It has been approved for systemic use in colon carcinomas (4). Its "off label" use in ophthalmology has evolved from the treatment of age-related macular degeneration (ARMD) to proliferative diabetic retinopathy (PDR) and macula oedema (5-8). Bevacizumab is also an anti-vascular endothelial growth factor (VEGF) agent which reduces permeability and allows resorption of subretinal fluid.
\end{abstract}

Keywords: Bevacizumab, breast carcinoma, choroidal metastasis, intravitreal injection

WIMJ Open 2014; 1 (2): 67

\section{CASE REPORT}

A 50-year old female presented in February 2014 with a twomonth history of gradual blurred vision in her right eye (only eye). She had breast cancer in 2009 and underwent a radical mastectomy (2010) and radiation (2011). Three months prior to presentation, she developed bone metastasis, but opted not to have chemotherapy.

Her best corrected visual acuity was 20/50 in the right eye and she could only visualize hand motions in the left eye. The left eye was amblyopic, with poor vision from birth and she had an esotropia (convergent squint) and a white cataract obscuring the fundal view. The right eye had a large 'creamish' elevated choroidal mass with neurosensory detachment, 6 disc diameters in diameter in the macula and also superior to the disc (Fig. 1a). B scan ultrasound of the left eye revealed multiple subretinal hyperechoic areas in the

From: Ophthalmology Division, Department of Surgery, Radiology, Anaesthesia and Intensive Care, Faculty of Medical Sciences, The University of the West Indies, Kingston 7, Jamaica, West Indies.

Correspondence: Ophthalmology Division, Department of Surgery, Radiology, Anaesthesia and Intensive Care, Faculty of Medical Sciences, The University of the West Indies, Kingston 7, Jamaica, West Indies. Fax: 876-702-4432, e-mail: lizettemowatt@yahoo.com

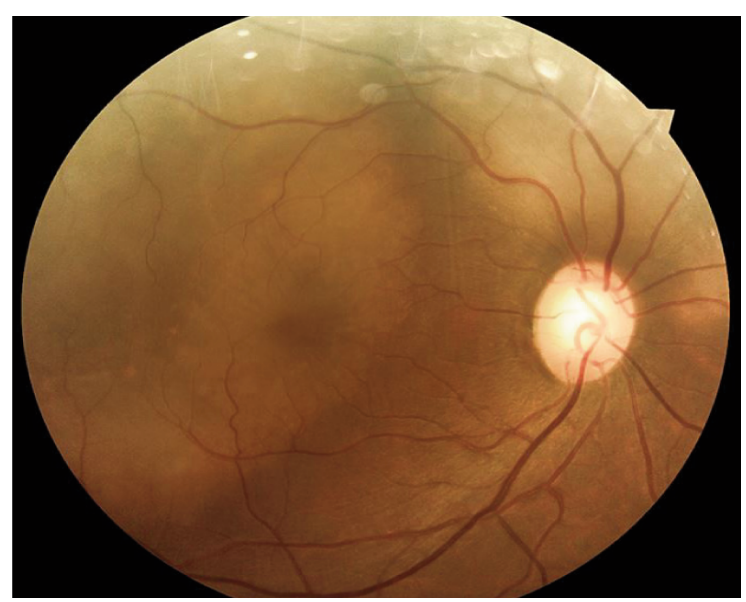

Fig. 1a: Right fundus pre-intravitreal bevacizumab.

macula area. An optical coherence tomography (OCT) scan of the right eye showed a solid choroidal mass in the macula with subretinal fluid [foveal thickness $502 \mu \mathrm{m}$ ] (Fig. 2a).

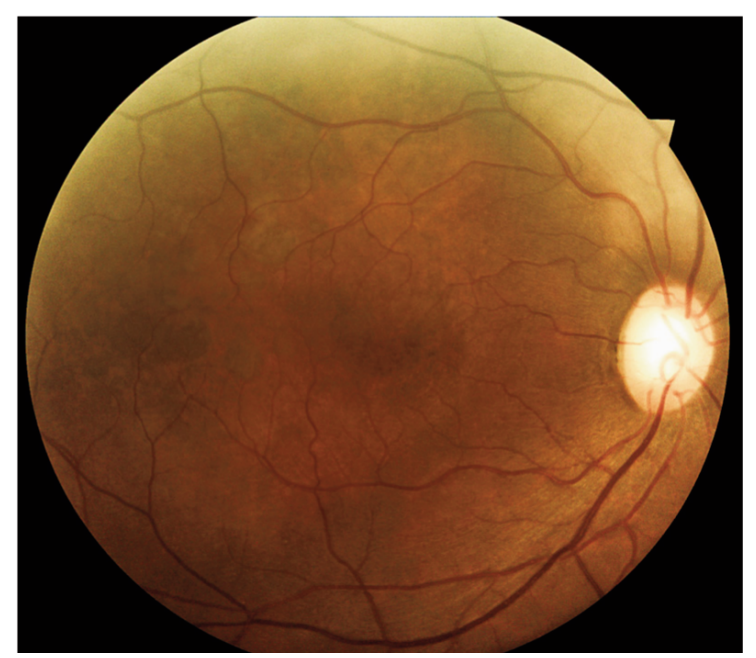

Fig. 1b: Right fundus 4/52 post-intravitreal bevacizumab.

She refused chemotherapy, but wanted visual improvement in her only functioning eye (right eye). She underwent right intravitreal bevacizumab injection $(1.25 \mathrm{mg}$ in $0.05 \mathrm{ml})$. The choroidal mass reduced in four weeks (Figs. 1b, 2b). At 
the six-week review, her vision had improved to $20 / 20$ in the right eye, and the choroidal metastasis in the posterior pole had resolved (Fig. 1c). Repeat OCT scan showed significant reduction in the foveal thickness to almost normal thickness [256 $\mu \mathrm{m}]$ (Fig. 2c).

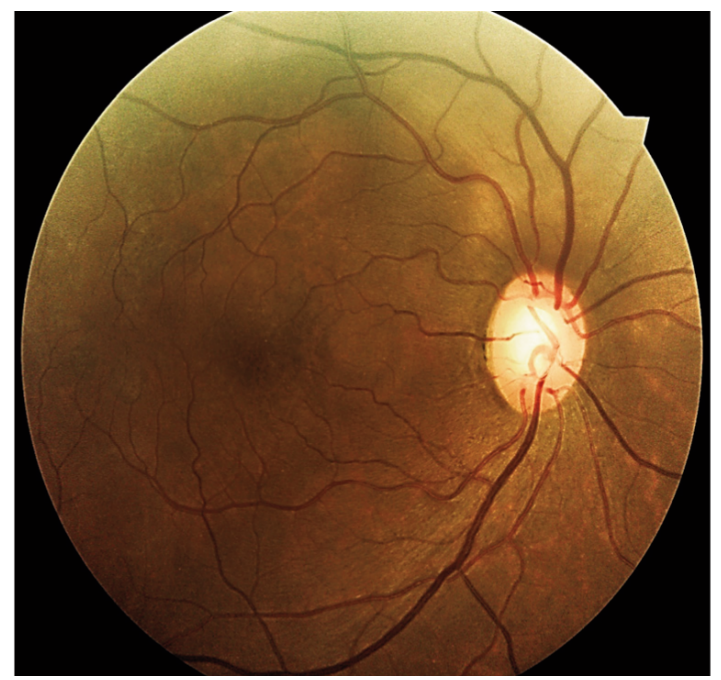

Fig. 1c: Right fundus 6/52 post-intravitreal bevacizumab.

Fig. 1: Fundus photographs of the right eye. (A) Pre-bevacizumab intravitreal injection with large elevated choroidal metastasis in the macular area. (B) Four weeks post-intravitreal injection with some resolution of the choroidal mass. (C) Six weeks post-intravitreal injection with resolution of macula metastases.

\section{DISCUSSION}

Bevacizumab, an anti-angiogenic agent, reduces vascular permeability when used intravitreally. The "off label" use of bevacizumab has increased over the past decade with evolving uses and varying concentrations for intraocular use. Amselem et al used $4 \mathrm{mg}(0.16 \mathrm{ml})$ of bevacizumab intravitreally to treat choroidal metastases from breast carcinoma and noted visual improvement from 20/100 to 20/60 in three weeks (9). Yao et al used adjuvant bevacizumab $2.5 \mathrm{mg}(0.1$ $\mathrm{ml}$ ) post chemotherapy with improvement from 20/400 to $20 / 30$ at six months (10). The index case had significant improvement with a non-adjuvant (no previous systemic chemotherapy), single intravitreal bevacizumab injection at a lower dosage $(1.25 \mathrm{mg} / 0.05 \mathrm{ml})$. This shows that intraocular use can be effective on metastasis at a very low dosage and volume $(0.05 \mathrm{ml})$.

Early treatment before significant exudation and tumour growth may yield good results, possibly due to less chronic destruction of the choroid and inner retinal layer. Monitoring with the high definition OCT is important in the management. Low dose and low volume intravitreal (intraocular) bevacizumab injection is safe and effective in treating choroidal metastasis from breast carcinoma. It also reduces the risk of systemic chemotherapy complications, especially in a patient with only one functioning eye, as in this case, and who achieved return of normal vision within a few weeks of treatment.

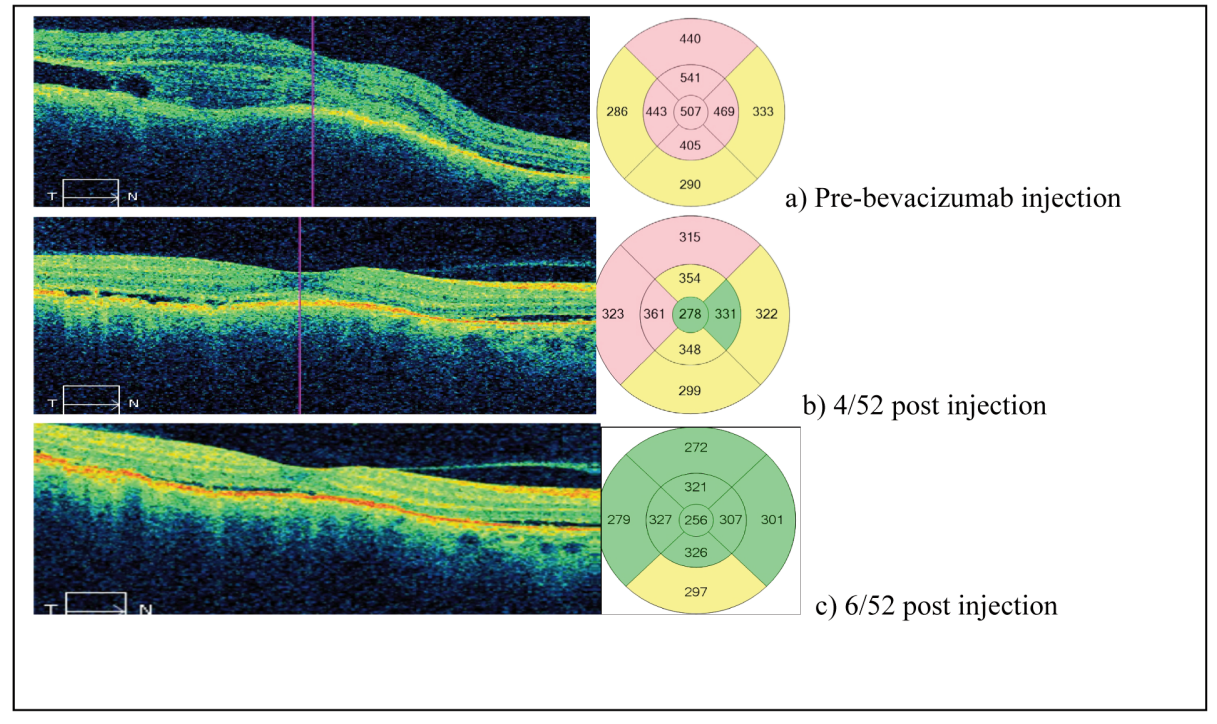

Fig. 2: High definition optical coherence tomogram (OCT) of the right central foveal thickness (CFT). (A) Pre-bevacizumab injection, CFT $507 \mu \mathrm{m}$. (B) 4/52 post-injection with CFT $278 \mu \mathrm{m}$. (C) 6/52 post injection with CFT return to normal thickness of $256 \mu \mathrm{m}$. 


\section{REFERENCES}

1. Chen CJ, McCoy AN, Brahmer J, Handa JT. Emerging treatments for choroidal metastases. Surv Ophthalmol 2011; 56: 511-21.

2. Manquez ME, Brown MM, Shields CL, Shields JA. Management of choroidal metastases from breast carcinomas using aromatase inhibitors. Curr Opin Ophthalmol 2006; 17: 251-6.

3. Zako M, Takeyama M, Naito E, Mizumoto K, Iwaki M. Choroidal and optic disc metastases from breast cancer and their response to combination pharmacotherapy with tamoxifen, cyclophosphamide hydrate, letrozole, and bevacizumab. J Ocul Pharmacol Ther 2012; 28: 89-93.

4. Giantonio BJ, Catalano PJ, Meropol NJ, O'Dwyer PJ, Mitchell EP, Alberts SR et al. Bevacizumab in combination with oxaliplatin, fluorouracil, and leucovorin (FOLFOX4) for previously treated metastatic colorectal cancer: results from the Eastern Cooperative Oncology Group Study E3200. J Clin Oncol 2007; 25: 1539-44.

5. Zhang XY, Guo XF, Zhang SD, He JN, Sun CY, Zou Y et al. Comparison of bevacizumab and ranibizumab in age-related macular degeneration: a systematic review and meta-analysis. Int J Ophthalmol 2014; 7: 355-64. doi: 10.3980/j.issn.2222-3959.2014.02.30. eCollection 2014.

6. Braithwaite T, Nanji AA, Lindsley K, Greenberg PB. Anti-vascular endothelial growth factor for macular oedema secondary to central retinal vein occlusion. Cochrane Database Syst Rev 2014; 5: CD007325. doi: 10.1002/14651858.CD007325.pub3.

7. Mitchell P, Wong TY. Diabetic Macular Edema Treatment Guideline Working Group. Management paradigms for diabetic macular edema Am J Ophthalmol 2014; 157: 505-13.e1-8. doi: 10.1016/j.ajo.2013. 11.012. Epub 2013 Nov 19.
8. Cintra LP, Costa RA, Ribeiro JA, Calucci D, Scott IU, Messias A et al. Intravitreal bevacizumab (Avastin) for persistent new vessels in diabetic retinopathy (IBEPE study): 1-year results. Retina 2013; 33: 1109-16. doi: 10.1097/IAE.0b013e31827b63f3.

9. Amselem L, Cervera E, Díaz-Llopis M, Montero J, Garcia-Pous M, Udaondo $\mathrm{P}$ et al. Intravitreal bevacizumab (Avastin) for choroidal metastasis secondary to breast carcinoma: short-term follow-up. Eye (Lond) 2007; 21: 566-7.

10. Yao HY, Horng CT, Chen JT, Tsai ML. Regression of choroidal metastasis secondary to breast carcinoma with adjuvant intravitreal injection of bevacizumab. Acta Ophthalmol 2010; 88: e282-3. doi: 10.1111/j.1755-3768.2009.01684.x.

Submitted 10 May 2014

Accepted 06 Jun 2014

Published 04 Sep 2014

Online: http://myspot.mona.uwi.edu/wimjopen/article/1592

(c) Mowatt 2014.

This is an open access article made freely available under Creative Commons Attribution 4.0 International (CC BY 4.0). Users are free to share, copy and adapt this work as long as the copyright holder (author) is appropriately and correctly credited. See http://creative commons.org/licences/by/4.0/deed.en_us for more information. 